Volume 9, No.3, May - June 2020

International Journal of Advanced Trends in Computer Science and Engineering

Available Online at http://www.warse.org/IJATCSE/static/pdf/file/ijatcse68932020.pdf

https://doi.org/10.30534/ijatcse/2020/68932020

\title{
Blockchain Framework for Securing E-Learning System
}

\author{
Millicent N. Ubaka-Okoye ${ }^{1}$, Ambrose A. Azeta ${ }^{2}$, Aderonke A. Oni ${ }^{2}$, Hilary I. Okagbue ${ }^{3}$, \\ Olanike S. Nicholas-Omoregbe ${ }^{4}$, Felix Chidozie ${ }^{5}$ \\ ${ }^{1}$ Department of Computer Science \& IT, Bells University of Technology, Ota, Nigeria \\ ${ }^{2}$ Department of Computer Science \& Information Sciences, Covenant University, Ota, Nigeria, \\ ${ }^{3}$ Department of Mathematics, Covenant University, Ota, Nigeria, "hilary.okagbue@ covenantuniversity.edu.ng \\ ${ }^{4}$ Department of Sociology, Covenant University, Ota, Nigeria \\ ${ }^{4}$ Department of Political Science \& International Relations, Covenant University, Ota, Nigeria
}

\begin{abstract}
This paper recommends a blockchain framework that secures the e-learning platform. The proposed framework was used to build a widely manageable and safe data delivery facility that will connect to existing educational data. Institutions can simply have amassed their data history without demanding a copy from central servers. The proposed blockchain framework enhances data security and removes trust concerns amongst users or between third-party institutions accessing applications and services. Data distribution can be used with smart contracts to warranty that institutions will continue to be in control of their data entrance, are alert of the source of collected data sources, and are up-to-date when their data is $\log$ on by others. Immutable audit logs are generated through data source and contact history to keep institutions informed of the time their data are retrieved. Blockchain has the potential that could provide a system with massive openness, online secure database that e-learning platforms needed. The blockchain can be implemented on different learning platforms based on the information security policies of the institutions.
\end{abstract}

Key words: Blockchain, education, e-learning, online, security, framework, privacy, trust.

\section{INTRODUCTION}

Blockchain emerged from Nakamoto [1] concept of the bitcoin, which is relatively a new innovative solution technology for securing records, storage, and transmission from end to end trustworthiness decentralized systems [2]. The decentralized interaction is mostly supported by scalable architectures with security and distributed trust [3]. Decentralization ensures that the process of managing data is not centralized and is not outsourced or control by any third party organization [4]. Any modification of data must be verified by all the concerned parties [5]. The emergence of cryptocurrencies was the first fruits of the application of blockchain technology [6], which ensures that the system is distributed and redundant, making it hard for transactions to be faked, duplicated, or rescinded [7].

The application of blockchain has further been extended to other areas such as medicine, smart contract [8], quality assurance [9], procurement [10-11], credit encryption, healthcare [12-13] and others. Moreover, blockchain is a strategy against social engineering.

The application of blockchain technology in education is equally an emerging research area as few works have been done on that area and hence a likely development in e-learning is typically online education and virtual learning [14]. Blockchain technology has proven to be more efficient in securing educational data than other methods, hence, the use has aided in implementing bring your own device (BYOD) in schools [15].

The blockchain technology can be used to store educational archives in a trustworthiness decentralized system, offering reliable digital certificates, recognize education resource sharing with smart contracts, and protect academic materials using data encryption [16-17]. Other benefits of using blockchain are immutability, reliability and data integrity [18].

The use of blockchain technology in educational institutions has many benefits such as the following:

a). To protect intellectual property which is a strategy against litigation and legal action arising from copyright infringements [19]. This will ensure accountability [20].

b). To improve the image and reputation of academic organizations [21].

c). To ensure that academic data are protected against unauthorized modifications [22-23] such as certificate racketeering, certificate tampering and falsification [24-25].

d). Speeding up the processing of university academic transcripts [26] and transfer of academic records between institutions [27-28].

e). To ensure transparent graduation requirements that cannot be tampered with without proper authorization [29]. This is a part of the protection and proper verification of students' historical records [30]. 
f). Verification of academic credentials [31], for example, during the admission process [32-33] and distributed registry [34].

g). To ensure credulity in competency assessment [35] and professional ability assessments [36].

g). Verification of the authenticity of academic accreditation [37-38].

h). Evaluation of learning itineraries [39].

i). Academic advising and to ensure confidentiality between students and tutors [40].

The key difficulties of the implementation of blockchain technology in education are awareness [41] and low level of ICT adoption, especially in developing countries [42]. Moreover, it has been adjudged to be too technical and difficult to understand [43]. Although, some learning kits have been proposed to ease the mode of implementation [44]. A combination of data extraction with blockchain has been identified to be one way to ease implementation and to extend the use of blockchain technology [45]. The skill required to ensure its adoption and subsequent implementation may not be available especially in developing countries. The risk involved in the implementation can be seen in [46]. One such risks are the erosion of other forms of assessment [47]. Despite the challenges, research has indicated that the blockchain technology will continue to be integrated with educational practice because of the aforementioned advantages [48-49].

This work recommends a blockchain-based framework that will secure e-learning system, which can be implemented by any educational institution to enhance privacy, security and remove trust concerns amongst users or between third-party institutions accessing applications and services. The distributed e-learning framework network will be studied by the existing node of the network and be allowed towards initializing blockchain ID of fresh users and network node that will register every fresh user and issue ID and a blockchain address wallet. Then users with authentic ID can access their records and data from anywhere and everywhere.

\section{BLOCKCHAIN TECHNOLOGY}

It is an innovating new generation internet that is immutable, decentralized, transparent, auditable, persistent and secured. It is a distributed database that multiple parties share and everyone can trust. Each party participating in the transactions of the network maintains a personal copy of the database. This database has automatic trust, tamper-proof, shared data, transparent and resilient.

\subsection{E-Learning Standards Platforms and Systems Frameworks}

Skills and knowledge are progressively inserted in the organizations and courses of our educational institutions for building locations for learning. Such locations now complement out-of-date classroom-based learning (called Blended learning) and can be used to assist conventional distance Learning. E-learning data supervision depends on this expertise to sustain developments. Though this expertise has the prospective in advancing educational activities. This perspective can be realized if the educational activities remain established on sound methodological infrastructure - an e-Learning Framework, which serves as a base for the building of e-Learning systems that were built on a centralized network. This section will commence with a look at different e-learning frameworks for their development.

\subsection{E-Learning Frameworks}

The development is done by organizations using implementation infrastructures such as a flexible service-oriented approach, separately identified service that can locate one or more open specifications or standards used in the service implementation. According to the United Kingdom's Joint Information Systems Committee (JISC), Australian Department of Education Science and Training (DEST) and Industry Canada (IC) presented a framework that is based on a service-oriented approach that was accessible for the improvement of integrated systems.

The framework is based on the Learning Technologies System Architecture (Architecture and Reference Model Working Group, IEEE) developed by the IEEE and other standards organizations such as Aviation Industry CBT Committee (AICC), IMS Global Learning Consortium (IMS) and Advanced Distributed Learning Network (ADL). This conceptual model framework seems to have been captured in the framework presented in Figure 1. Figure 2 below shows another framework proposed by Britain and Liber [50]. The authors developed the framework in 1999 and were revised in 2004. Originally it was established in order to ease the take-up and use of virtual learning environments (VLEs) through so as to promote the educational system.

In these cited examples of e-learning framework, there is an urgent need to build a trustable system that users will have confidence in as it relates to reliability and availability of users' and instructors' information security and privacy. Blockchain technology will handle users and instructors' information security and privacy challenges in e-learning framework also detect potential threats to message and channel networks in an open distributed system, such as message integrity and user privacy. The existing e-learning framework lacks control for integrated safety that enhances security and privacy. It lacks security also by having a single centralized system managing the records.

This paper recommends a framework of a distributed e-learning system using the blockchain technology that will create a widely manageable and safe data distribution service that will link to existing educational data. Institutions can simply have amassed their data history without demanding a copy from central servers. The blockchain framework enhances data security and removes trust concerns amongst users or between third-party institutions accessing applications and services. 


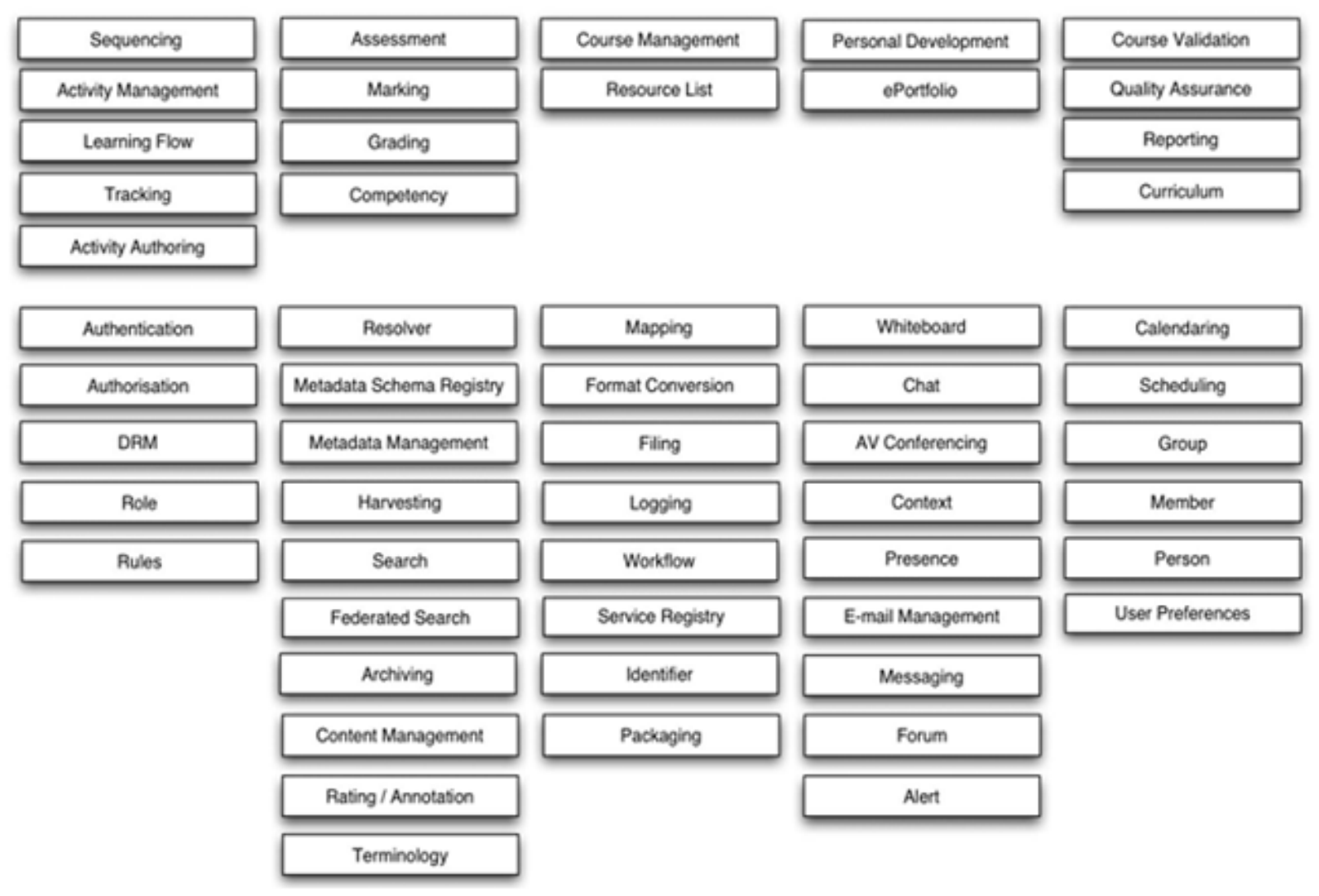

Figure 1: The e-learning Framework

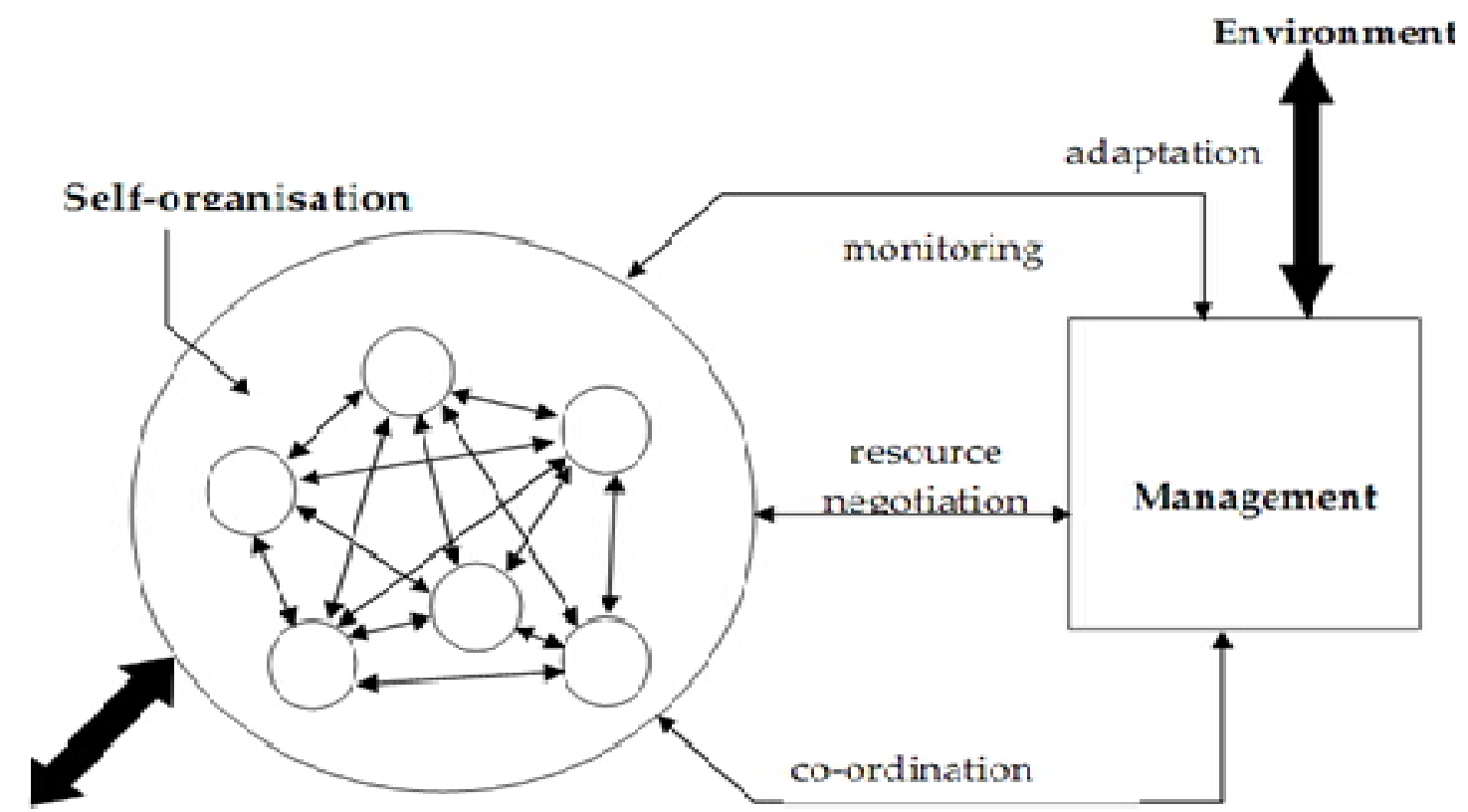

\section{Environment}

Figure 2: Britain \& Liber simplified adaptation of Beer's system model [50] 


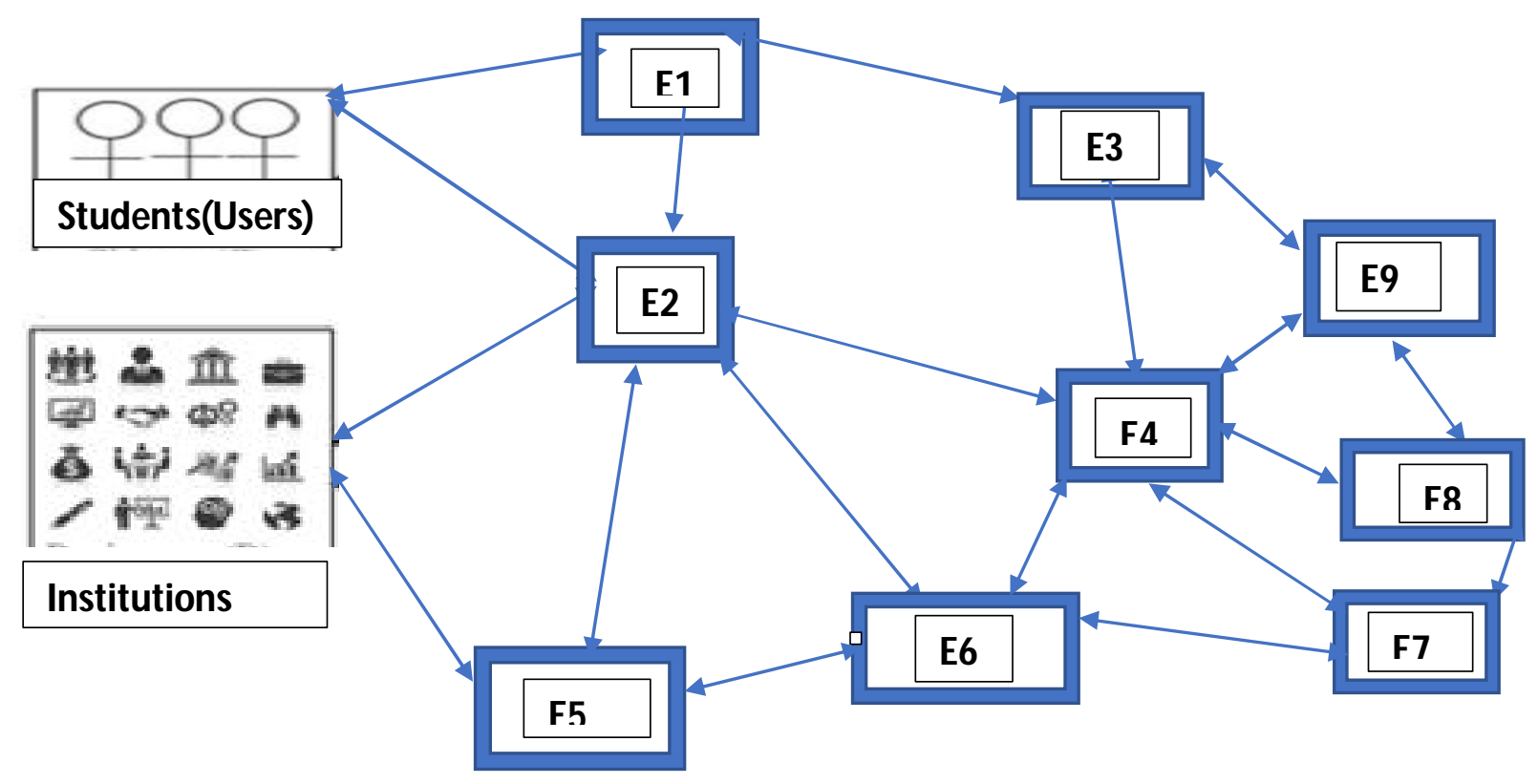

Figure 3: The Blockchain-Based e-learning Network Framework

Data distribution can be used with smart contracts to warranty that institutions will continue to be in control of their data entrance, are alert of the source of collected data sources, and are up-to-date when their data is $\log$ on by others [51]. Immutable audit logs are generated through data source and contact history to keep institutions informed of the time their data are retrieved. Blockchain has the potential that could provide a system with massive openness, an online, secure database that e-learning platform needed.

\section{BLOCKCHAIN-BASED E-LEARNING SYSTEM}

The blockchain-based e-learning framework is showed in Figure 3. The "E" represents the e-learning node with its unique node number. The duple route arrow represents data communication amongst the institutions and students in a distributed transmission and authentication of data being accessed by students. The duple route arrow also states the model of a learning platform where users access their data without loss, accommodates a broader array of learning styles and goals. The connection of any new e-learning (E) node is authenticated by operators in the network. In addition, e-learning proofs are rewarded for setting up a private (permission) blockchain service. The number of e-learning proofs is proportional to the total number of records stored by a node in the blockchain network. Respectively, users have devoted e-learnings blockchain wallet to be rewarded with his /her proofs. Whenever a record is submitted, it will be transferred in terms of a stake to the person's blockchain address. This proof-of-stake protocol will register any node within the network as a representative. Adding a new block to the blockchain, the institutions that together make up the e-learning system vote for a representative that will authenticate the transactions and seal the block. The procedures were designed for security measures such as to avoid random nodes joining the network and generating new tokens. Usually when setting up a node the entire e-learning users' node approves the transactions (at least $50 \%$ consensus is needed). The private (permission) blockchain system enhances data security and excludes trust concerns amongst users.

\subsection{Fresh Node Creation}

In the blockchain network models we have full nodes and lightweight nodes [52]. Full nodes permit users in the network nodes have access to entire copies of the blockchain to fully authenticate transactions and blocks. Whereas light nodes do not have access to the entire copies, but only have access to genesis blocks to authenticate the transactions.

E-learning institutions' can link to a full network node while students can link to light nodes. The recommended e-learning new node network is in "Algorithm 1". Immediately a fresh node links the network, an efficient node creates ID wallet address (private and public keys) presented below In line "9" the created private key will be used for authenticating transactions (it must remain private and safe). Subsequently creating the address, an efficient node communicates to representative authenticating the fresh registration and allocating some e-learning proofs (registration record) in its wallet address. Then the fresh node registration is completed and announced to the entire network by the efficient representative (line 12-14). Once the fresh node collects information for setting up a network node. 
Henceforth the fresh node can be selected as a representative to authenticate transactions in the subsequent rotation. The procedure of adding a fresh node is accomplished only when a network node is effectively set up and announced by the efficient representative. Data security is improved through encrypted records spread through the network. As soon as a traitor node is recorded or observed as an institution node, it will not change the data because of the immutable features of the entire process.

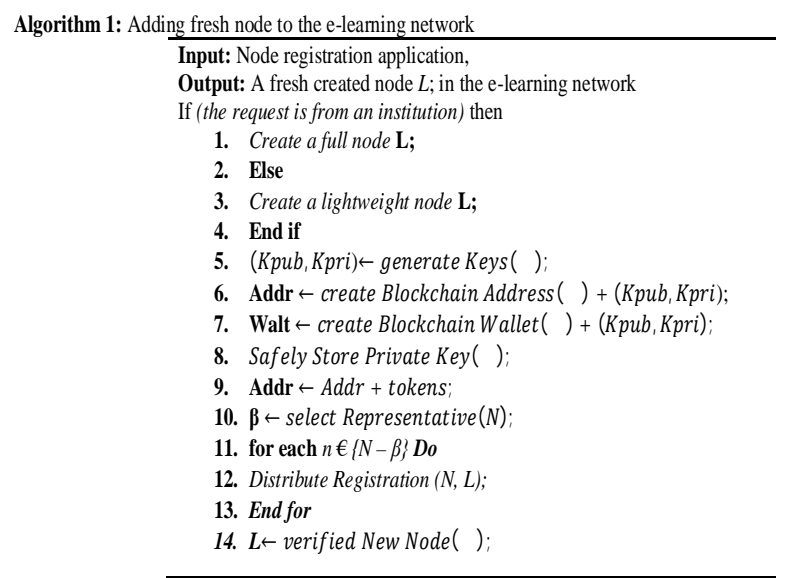

\subsection{Operator Registration}

Operators or Users that needs to have access to the e-learning portals must register through the process shown in "Algorithm 2" using their network devices. An operator will be assigned an ID and a fresh blockchain address is created using public and private keys as a proof of identity of the owner (lines 2 and 3). Then blockchain wallet designed for the fresh user is generated and announced to save each node ID address. The generated ID address wallet will be communicated to the users to confirm and used for transactions as its account. (it must remain private and safe).

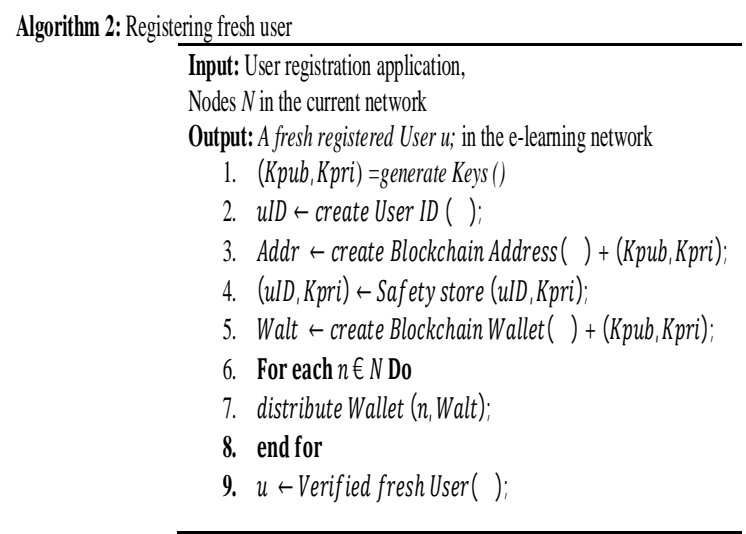

When a third party institution needs to access student's data. Firstly, ID address must be confirmed and authenticated. The institution also uses block web API to confirm the student's ID address. Every single e-learning operators are mandated to have a backup ID keys and keep them safe. When operators lose their ID key, a fresh ID address will be created and a request to one of the e-learning user nodes will be informed to transfer data from the old ID address to a freshly created ID address. The user's device and identity will be confirmed and authenticated when registered operators wants to access the network. Human errors and weak links in data storage and access that were characterized by e-learning system will dramatically reduce [53].

\subsection{Fresh Block Creation}

The creation of a fresh block is normally generated by one efficient representative who is nominated at random by order active and efficient members When a member misses a block, another member is tasked to create and authenticate the block to join the blockchain network. In Proof-of-stake (PoS), takes five seconds [54]. "Algorithm 3" shows the essential process involved in creating and joining fresh block to the blockchain using the $\mathrm{PoS}$ consensus algorithm.

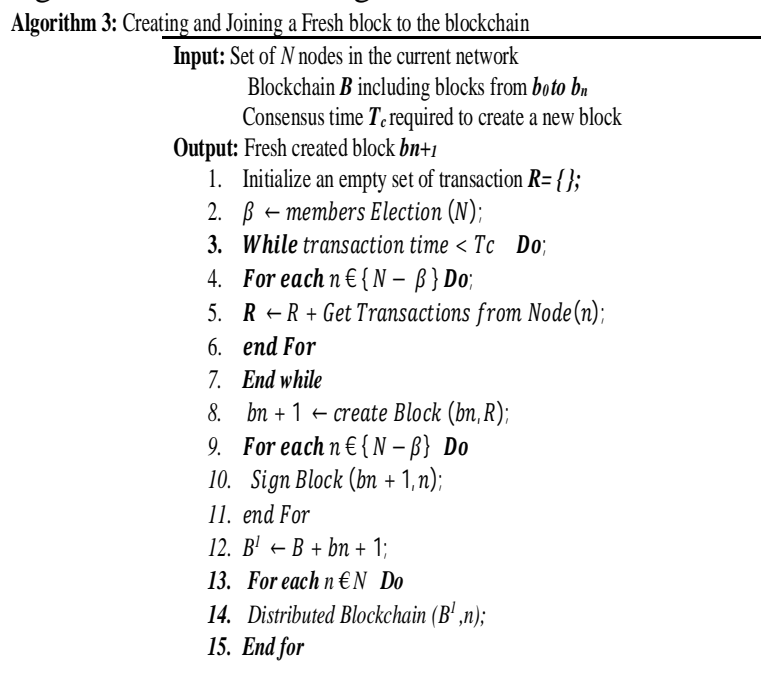

Tc. represents a block that is generated at an interval of time. Inside this interval, the block goes through the subsequent process. $\mathrm{R}$ represents an empty set of transactions. A representative is nominated to generate and authenticate the transactions for the blockchain. The process will continue until the nominated representative ends accepting new transactions from the block. Lastly, the nominated representative will gather the fresh block and distributes it to the network members for assessment and authentication. This process will give those nodes that nominated the representative to digitally sign the block to prove its accuracy. The confirmed block is returned to the members then joined to the local blockchain. However, the new block will be distributed to the network. Finally, e-learning institution nodes will be distributed in the network. 


\section{CONCLUSION}

The recommended e-learning framework for security and privacy using blockchain technology has proven to reduce the security and privacy threats experienced in e-learning platforms. Blockchain technology has the potential that could provide a system with massive openness, online, secure database that educational systems needed. Educational institutions should deploy this new innovative generation internet technology that is immutable, decentralized, transparent, auditable, persistent and protect the efficiency of the e-learning system. The paper is narrowed at the framework and academic discussion level, the future work is to implement the framework and further explore its potential on an active e-learning platform, such as the e-learning systems of distance learning, classroom learning, mobile learning, blended learning or online learning platforms. The implementation can be hindered by some infrastructural challenges that need to be addressed before blockchain technology will be deployed [55-60]. There is a need to find an appropriate version of blockchain technology in e-learning to accommodate the infrastructural challenges since blockchain technology is still at its nascent stage. Moreso, blockchain can also be integrated together with voice platform [61] for ease of communication through voice user interface. A discussion of health related ethical issues in blockchain might also form part of the future research [62].

\section{ACKNOWLEDGEMENT}

The research benefited from Covenant University sponsorship.

\section{REFERENCES}

1. Nakamoto, S. (2008). Bitcoin: A peer-to-peer electronic cash system. www.bitcoin.org/bitcoin.pdf

2. Taylor, P.J., Dargahi, T., Dehghantanha, A., Parizi, R.M. \& Choo, K.-K.R. (2019). A systematic literature review of blockchain cyber security. Digital Communications and Networks, 10.1016/j.dcan.2019.01.005.

3. Thomas, M. \& Chooralil, V.S. (2019). Security and privacy via optimised blockchain. International Journal of Advanced Trends in Computer Science and Engineering, 8(3), 415-418 https://doi.org/10.30534/ijatcse/2019/14832019

4. Turkanović, M., Hölbl, M., Košič, K., Heričko, M. \& Kamišalić, A. (2018). EduCTX: A blockchain-based higher education credit platform. IEEE Access, 6, 5112-5127.

5. Arndt, T. (2019). An overview of blockchain for higher education. Proceedings of the 11th Int. Joint
Conf. on Knowledge Discovery, Knowledge Engineering and Knowledge Management, Volume 3, pp. 231-235. https://doi.org/10.5220/0008343902310235

6. Krishna Chaitanya, A., Prasanthi, M.L. \& Sambasivarao, N. (2019). Cryptographic based message transfer using block chain technology. International Journal of Advanced Trends in Computer Science and Engineering, 8(1), 45-50, https://doi.org/10.30534/ijatcse/2019/1081.32019

7. Hoy, M.B. (2017). An Introduction to the Blockchain and Its Implications for Libraries and Medicine. Medical Reference Services Quarterly, 36(3), 273-279. https://doi.org/10.1080/02763869.2017.1332261

8. Bailon, M.R.M. \& Materum, L. (2019). International roaming services optimization using private blockchain and smart contracts. International Journal of Advanced Trends in Computer Science and Engineering, 8(3), 544-550.

https://doi.org/10.30534/ijatcse/2019/32832019

9. Katuk, N. (2019). The application of blockchain for halal product assurance: a systematic review of the current developments and future directions. International Journal of Advanced Trends in Computer Science and Engineering, 8(5), 1893-1902 https://doi.org/10.30534/ijatcse/2019/13852019

10. Thio-Ac, A., Serut, A.K., Torrejos, R.L., Rivo, K.D. \& Velasco, J. (2019). Blockchain-based system evaluation: The effectiveness of blockchain on E-procurements. International Journal of Advanced Trends in Computer Science and Engineering, 8(5), 2673-2676.

https://doi.org/10.30534/ijatcse/2019/122852019

11. Thio-Ac, A., Domingo, E.J., Reyes, R.M., Arago, N., Jorda, R., Jr. \& Velasco, J. (2019). Development of a secure and private electronic procurement system based on blockchain implementation. International Journal of Advanced Trends in Computer Science and Engineering, 8(5), 2626-2631.

https://doi.org/10.30534/ijatcse/2019/115852019

12. De Souza, J.I.M., Jr., De Araújo, D.S., Barbosa, G.V. \& Letouze, P. (2019). An International Accreditation System for Healthcare Professionals Based on Blockchain. Int. J. Info. Educ. Tech., 9(7), 462-469. https://doi.org/10.18178/ijiet.2019.9.7.1247

13. Lee, S.Y. (2019). Medical data framework using blockchain technology. International Journal of Advanced Trends in Computer Science and Engineering, 8(5), 2353-2358 https://doi.org/10.30534/ijatcse/2019/75852019

14. Arishi, H.A., Mavaluru, D. \& Mythily, R. (2018). Block chain technology and its applications for virtual education. Journal of Advanced Research in Dynamical and Control Systems, 10(13), 1780-1785.

15. Yeop, Y.H., Ali Othman, Z., Huda Sheikh Abdullah, S.N., Asmar Mokhtar, U., Paizi Fauzi, W.F. \& Ahmad, N. (2018). Key Factors to Implement BYOD in Schools. Proc. Cyber Resil. Conf., Art. no. 8626864. 
16. Sun, H., Wang, X. \& Wang, X. (2018). Application of blockchain technology in online education. Int. J. Emerging Technol. Learn., 13(10), 252-259. https://doi.org/10.3991/ijet.v13i10.9455

17. Holbl, M., Kamisalic, A., Turkanovic, M., Kompara, M., Podgorelec, B. \& Hericko, M. (2018). EduCTX: An Ecosystem for Managing Digital Micro-Credentials. Proc. of 28th EAEEIE Annual Conf., Art. no. 8534284.

18. Alammary, A., Alhazmi, S., Almasri, M. \& Gillani, S. (2019). Blockchain-based applications in education: A systematic review. Appl. Sci., 9(12), Art. no. 400. https://doi.org/10.3390/app9122400

19. Hori, M., Ono, S., Miyashita, K., Kobayashi, S., Miyahara, H., Kita, T., Yamada, T. \& Yamaji, K. (2018). Learning system based on decentralized learning model using blockchain and SNS. Proc. of the 10th Int. Conf. on Comp. Supp. Educ., Vol. 1, pp. 183-190. https://doi.org/10.5220/0006666901830190

20. Silva, S., Pires, F. \& Bernardino, J. (2019). Editorial platform in blockchain for application in higher education. Proc. of the 16th Int. Joint Conf. on e-Business and Telecom., Vol. 1, pp. 221-227.

21. Sharples, M. \& Domingue, J. (2016). The blockchain and kudos: A distributed system for educational record, reputation and reward. Lecture Notes in Computer Science, 9891, 490-496.

22. Li, T., Duan, B., Liu, D. \& Fu, Z. (2018). Design of outcome-based education blockchain. Int. J. of Performability Engineering, 14(10), 2403-2413. https://doi.org/10.23940/ijpe.18.10.p16.24032413

23. Al Harthy, K., Al Shuhaimi, F. \& Juma Al Ismaily, K.K. (2019). The upcoming Blockchain adoption in Higher-education: Requirements and process. 4th MEC Int. Conf. Big Data \& Smart City, Art. no. 8645599.

24. Karale, A.S. \& Khanuja, H. (2019). Implementation of blockchain technology in education system. Int. J. Recent Technology and Engineering, 8(2), 3823-3828. https://doi.org/10.35940/ijrte.B2462.078219

25. Budhiraja, S. \& Rani, R. (2020). TUDocChain-Securing Academic Certificate Digitally on Blockchain. Lecture Notes in Networks and Systems, 98, 150-160.

26. Arndt, T. (2018). Empowering university students with blockchain-based transcripts. Proc., 15th Int. Conf. Cogn. \& Explor. Learn. in the Digital Age, pp. 399-400.

27. Yumna, H., Khan, M.M., Ikram, M. \& Ilyas, S. (2019). Use of Blockchain in Education: A Systematic Literature Review. Lecture Notes in Computer Science, 11432, 191-202. https://doi.org/10.1007/978-3-030-14802-7_17

28. Kanan, T., Obaidat, A.T. \& Al-Lahham, M. (2019). SmartCert BlockChain Imperative for Educational Certificates. Proc. of IEEE Jordan Int. Joint Conf. on Elect. Engine. Info. Tech., Art. no. 8717505, pp. 629-633.
29. Duan, B., Zhong, Y. \& Liu, D. (2017). Education application of blockchain technology: Learning outcome and meta-diploma. Proc. of the 23rd IEEE Int. Conf. on Parallel and Distributed Systems, 814-817. https://doi.org/10.1109/ICPADS.2017.00114

30. Harrington, K. (2019). Distributed autonomous learning framework. Proc. of SPIE - The Int. Society for Optical Engineering, 11013, Article number 110130M. https://doi.org/10.1117/12.2519963

31. Arenas, R. \& Fernandez, P. (2018). CredenceLedger: A Permissioned Blockchain for Verifiable Academic Credentials. Proceedings of IEEE Int. Conf. on Engine., Technol. and Innovation, Art. no. 8436324.

32. Ghaffar, A. \& Hussain, M. (2019). BCEAP - A blockchain embedded academic paradigm to augment legacy education through application. ACM Int. Conf. Proc. Series, Article number 3342036. https://doi.org/10.1145/3341325.3342036

33. Mori, K. \& Miwa, H. (2020). Digital university admission application system with study documents using smart contracts on blockchain. Advances in Intelligent Systems and Computing, 1035, 172-180.

34. Naumova, O.A., Svetkina, I.A. \& Naumov, D.V. (2019). The main limitations of applying blockchain technology in the field of education. Int. Sci. and Technol. Conf., Article number 8725411.

35. Wanotayapitak, S., Saraubon, K. \& Nilsook, P. (2019). Process design of cooperative education management system by cloud-based blockchain E-Portfolio. Int. J. Online \& Biomed. Engine., 15(8), 4-17. https://doi.org/10.3991/ijoe.v15i08.10374

36. Zhao, W., Liu, K. \& Ma, K. (2019). Design of Student Capability Evaluation System Merging Blockchain Technology. Journal of Physics: Conference Series, 1168(3), Article number 032123.

37. Kamišalić, A., Turkanović, M., Mrdović, S. \& Heričko, M. (2019). A Preliminary Review of Blockchain-Based Solutions in Higher Education. Communications in Computer and Information Science, 1011, 114-124.

38. Mikroyannidis, A., Domingue, J., Bachler, M. \& Quick, K. (2018). Smart Blockchain Badges for Data Science Education. Proc. Front. Educ. Conf., Art. no. 86590124. https://doi.org/10.1109/FIE.2018.8659012

39. Vargas, P.R. \& Soriano, C.L. (2019). Blockchain in the university: A digital technology to design, implement and manage global learning itineraries. Digital Education Review, 35, 130-150.

40. Salem, M., Samara, K. \& Aldhaheri, M.S. (2019). A novel integrated framework for securing online instructor-student communication. International Journal of Grid and Utility Computing, 10(1), 42-52.

41. Gong, X., Liu, X., Jing, S., Xiong, G. \& Zhou, J. (2019). Parallel-Education-Blockchain Driven Smart Education: Challenges and Issues. Proc. of Chinese Automation Congress, Art. no. 8623198, 2390-2395. 
42. Mseteka, L. \& Phiri, J. (2019). A secure model for storage and dissemination of examination results: A case study of Zambia technical education vocational and entrepreneurship training authority. Journal of Computer Science, 15(2), 221-234. https://doi.org/10.3844/jcssp.2019.221.234

43. Srivastava, G., Dhar, S., Dwivedi, A.D. \& Crichigno, J. (2019). Blockchain Education. IEEE Canadian Conf. of Electrical \& Computer Engineering, Art. no. 8861828.

44. Kamal, N., Saad, M.H.M., Kok, C.S. \& Hussain, A. (2018). Towards revolutionizing stem education via IoT and blockchain technology. International Journal of Engineering and Technology, 7(4), 189-192.

45. Juricic, V., Radoševic, M. \& Fuzul, E. (2019). Creating student's profile using blockchain technology. Proc. of 42nd Int. Convention on Info. \& Comm. Tech., Electr. \& Microelectronics, Art. no. 8756687, pp. 521-525.

46. Yakovenko, I., Kulumbetova, L., Subbotina, I., Zhanibekova, G. \& Bizhanova, K. (2019). The blockchain technology as a catalyst for digital transformation of education. Int. J. Mech. Engine. Tech., 10(1), 886-897.

47. Williams, P. (2019). Does competency-based education with blockchain signal a new mission for universities? J. Higher Educ. Policy and Manag., 41(1), 104-117. https://doi.org/10.1080/1360080X.2018.1520491

48. Li, L. \& Wu, X. (2019). Research on school teaching platform based on blockchain technology. 14th Int. Conf. Comp. Sci. Educ., Art. no. 8845353, pp. 38-43. https://doi.org/10.1109/ICCSE.2019.8845353

49. Ammbika, V.M. \& Rao, D.S. (2019). Block-chain technology -security, platforms. Int. J. Recent Technology and Engineering, 8(11), 3512-3518.

50. Britain \& Liber (2004). A Framework for the Pedagogical Evaluation of Virtual Learning Environment. Available at: [http://www.jisc.ac.uk /uploaded_documents/jtap-041.doc.

51. Gupta, M. (2017). Blockchain for Dummies, IBM Limited Edition. Available at: https://www-01.ibm.com/ common/ssi/cgi-bin/ssialias?htmlfid=XIM12354USEN.

52. Antonopoulos, A. M. (2014). Mastering Bitcoin: Unlocking digital cryptocurrencies. Newton: O'Reilly Media, Inc.

53. Luiijf, E.A. (2012). Understanding Cyber Threats and Vulnerabilities. Critical Infrastructure Protection. https://doi.org/10.1007/978-3-642-28920-0_4

54. Zheng, Z., Xie, S., Dai, H., Chen, X., \& Wang, H. (2017). An overview of blockchain technology: Architecture, consensus, and future trends. In Proceedings of IEEE International Congress on Big Data, pp. 557-564.

55. Osuagwu, O.E., Chukwudebe, G. \& Eleoba, P. (2003). Expanding Educational Opportunities to the Hinterlands through Vsat--Based Internet Technology. A Proceeding of the Nigeria Computer Society, Vol 14, pp. 233-249.
56. Omuh, I.O., Amusan, L.M., Ojelabi, R.A., Afolabi, A.O. \& Tunji-Olayeni, P.F. (2017). Learning difficulties in the study of structural analysis in tertiary institutions. Turkish Online Journal of Educational Technology, 2017(November Special Issue INTE), 395-403.

57. Azeta, A., Misra, S., Adewumi, A., Omoregbe, N. \& Banjo, E. (2016). Development of an automated E-campus system. International Journal of Control Theory and Applications, 9(23), 347-353.

58. Opanuga, A.A., Okagbue, H.I., Oguntunde, P.E., Bishop, S.A. \& Ogundile, O.P. (2019). Learning analytics: Issues on the pupil-teacher ratio in public primary schools in Nigeria. International Journal of Emerging Technologies in Learning, 14(10), pp. 180-199.

https://doi.org/10.3991/ijet.v14i10.10129

59. Domingue, J. (2017). Education's new kid on the block. Available at: /www.open.ac.uk/research/main /news/educations-new-kid-block.

60. Elisa, N., Yang, L., Chao, F. \& Cao, Yi. (2018). A framework of blockchain-based secure and privacy-preserving E-government system, pp. 203-214. Springer. https://doi.org/10.1007/s11276-018-1883-0

61. Azeta A.A. (2013). Developing a Computerized VoiceXML-Based Application For E- Education: Design, Implementation and Evaluation. A textbook published by Lambert Academic Publishing, Germany. Project ID (66759). ISBN: 978-3-659-24716-3.

62. Osamor, V. C., Azeta, A. A., \& Ajulo, O. O. (2014). Tuberculosis-Diagnostic Expert System: An architecture for translating patients information from the web for use in tuberculosis diagnosis. Health Informatics Journal, 20(4), 275-287. https://doi.org/10.1177/1460458213493197 